\title{
New phenolic derivatives from Vernonia mapirensis Gleason
}

\author{
Luis Morales-Escobar ${ }^{\mathrm{a}}$, Alessandra Braca ${ }^{\mathrm{b}}$, Cosimo Pizza $^{\mathrm{c}}$, and \\ Nunziatina De Tommasi*,c \\ ${ }^{a}$ Istituto de Investigaciones Quimicas, Universidad Mayor de San Andres, Calle 27, esq. A. Bello, \\ Cota Cota Campus Universitario, IIQ, Casilla 303, La Paz, Bolivia \\ ${ }^{b}$ Dipartimento di Chimica Bioorganica e Biofarmacia, Università di Pisa, Via Bonanno 33, 56126 \\ Pisa, Italy \\ ${ }^{c}$ Dipartimento di Scienze Farmaceutiche, Università di Salerno, Via Ponte Don Melillo, 84084 \\ Fisciano (SA), Italy \\ E-mail:_detommasi@unisa.it
}

\begin{abstract}
Six new phenolic derivatives, including four flavonoids and two benzofuranones, were isolated from the aerial part extracts of Vernonia mapirensis Gleason (synonymous Lepidaploa mapirensis (Gleason) H. Robinson, Vernonia trichoclada Gleason, Asteraceae family), together with four known flavonoids. Their structural elucidation was achieved by extensive spectroscopic methods, 1D- $\left({ }^{1} \mathrm{H},{ }^{13} \mathrm{C},{ }^{13} \mathrm{C}\right.$ DEPT, TOCSY, ROESY) and 2D-NMR experiments (DQF-COSY, HSQC, $\mathrm{HMBC}$ ) as well as ESI-MS analysis.
\end{abstract}

Keywords: Vernonia mapirensis, Asteraceae, flavonoids, benzofuranones

\section{Introduction}

Vernonia genus (Asteraceae family) comprises tropical and sub-tropical species widespread through both the hemispheres. ${ }^{1}$ Previous phytochemical studies on this genus led to the isolation and characterization of flavonoids, steroidal glycosides, and sesquiterpenes. ${ }^{2-5}$ In our continuing studies on the chemistry of Vernonia species, we selected V. mapirensis Gleason (synonymous Lepidaploa mapirensis (Gleason) H. Robinson, Vernonia trichoclada Gleason), a species native to Bolivia where is used traditionally for the preparation of anti-inflammatory remedies.

The aim of our work was to carry out the phytochemical investigation of $V$. mapirensis aerial parts and herein we report the isolation and structural characterization of six new phenolic derivatives, including four flavonoids (1-4) and two benzofuranones (5-6), from the methanol and chloroform-methanol extracts of the title plant, on the basis of extensive spectroscopic and spectrometric analysis (1D-NMR, 2D-NMR, ESI-MS). 


\section{Results and Discussion}

Compound 1 was isolated as a yellow amorphous powder. Its molecular formula was established as $\mathrm{C}_{36} \mathrm{H}_{36} \mathrm{O}_{19}$ by means of ESI-MS ([M-H] $]$ peak at $\mathrm{m} / z$ 771), ${ }^{13} \mathrm{C},{ }^{13} \mathrm{C}$-DEPT NMR, and elemental analysis. Analysis of $600 \mathrm{MHz}$ NMR spectra suggested a flavonoid skeleton for compound $\mathbf{1}$. The ${ }^{1}$ H-NMR spectrum (Table 1) indicated a 5,7-dihydroxylated pattern for ring A (two meta-coupled doublets at $\delta 6.16$ and $6.33, J=1.5 \mathrm{~Hz}$ ) and a $3^{\prime}, 4^{\prime}$-dihydroxylation pattern for ring B (ABX system signals at $\delta 6.97, \mathrm{~d}, J=8.5 \mathrm{~Hz} ; 7.84, \mathrm{dd}, J=8.5,2.0 \mathrm{~Hz} ; 7.65, \mathrm{~d}, J=2.0 \mathrm{~Hz}$ ), allowing the aglycon to be recognized as quercetin. ${ }^{6}$ The ${ }^{1} \mathrm{H}-\mathrm{NMR}$ spectrum of $\mathbf{1}$ also showed signals ascribable to sugar moieties and a $p$-coumaroyl residue (Table 1). Two anomeric protons arising from the sugar moieties appeared at $\delta 5.26$ and 4.88 each $(1 \mathrm{H}, \mathrm{d}, J=7.5 \mathrm{~Hz})$, which correlated respectively with signals at $\delta 103.4$ and $104.7 \mathrm{ppm}$ in the HSQC spectrum. All the ${ }^{1} \mathrm{H}-$ and ${ }^{13} \mathrm{C}-\mathrm{NMR}$ signals of $\mathbf{1}$ were assigned using 1D-TOCSY, DQF-COSY, HSQC, and HMBC experiments. Complete assignments of proton and carbon chemical shifts of the sugar portion were accomplished by DQFCOSY and 1D-TOCSY experiments and allowed the identification of the sugars as two $\beta$-Dglucopyranosyl units, one terminal and one esterified. The configurations of the sugar units were assigned after hydrolysis of 1 with $1 \mathrm{~N} \mathrm{HCl}$. The hydrolysate was trimethylsilylated, and GC retention times compared with those of authentic sugar samples prepared in the same manner. The lower field shifts of $\mathrm{H}_{2}-6$ "' ( $\delta 4.32$ and 4.23) of one glucosyl unit suggested the substitution site of the $p$-coumaroyl moiety. Unequivocal information could be obtained by 2D-NMR spectra; the HMBC experiment indicated correlations between $\delta 5.26$ (H-1"') and 135.6 (C-3), $\delta 4.88$ (H-1") and $148.0\left(\mathrm{C}-3^{\prime}\right), \delta 4.32$ and $4.23\left(\mathrm{H}_{2}-6^{\prime \prime \prime}\right)$ and 168.5 (COO). Thus, the structure of 1 was determined as quercetin 3-O-(6"-p-coumaroyl)- $\beta$-D-glucopyranoside-3'- $O$ - $\beta$-D-glucopyranoside.

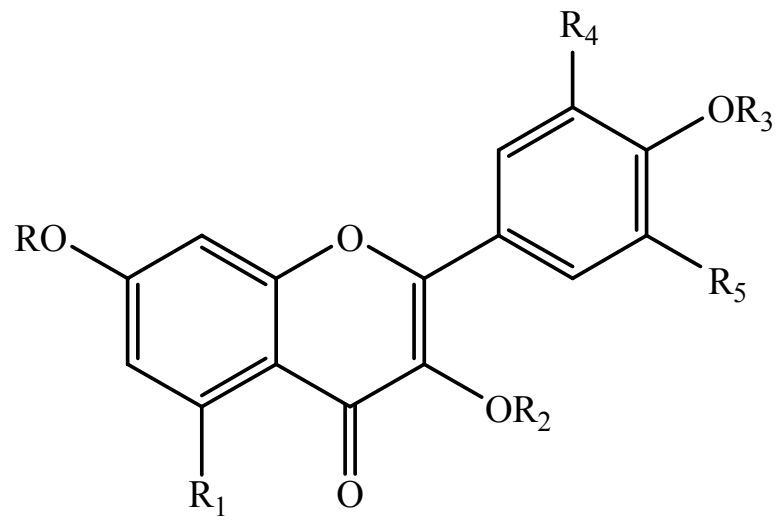

$\begin{array}{lllll}1 & \mathrm{R}=\mathrm{R}_{3}=\mathrm{R}_{5}=\mathrm{H} & \mathrm{R}_{1}=\mathrm{OH} & \mathrm{R}_{2}=(6 "-p \text {-coumaroyl }) \mathrm{glc} & \mathrm{R}_{4}=O \text {-glc } \\ 2 & \mathrm{R}=\mathrm{R}_{4}=\mathrm{R}_{5}=\mathrm{H} & \mathrm{R}_{1}=\mathrm{OH} & \mathrm{R}_{2}=(6 "-p \text {-coumaroyl }) \mathrm{glc} & \mathrm{R}_{3}=\mathrm{Me} \\ \mathbf{3} & \mathrm{R}=\mathrm{R}_{2}=\mathrm{Me} & \mathrm{R}_{1}=\mathrm{OMe} & \mathrm{R}_{3}=\mathrm{R}_{5}=\mathrm{H} & \mathrm{R}_{4}=O \text {-glc } \\ 4 & \mathrm{R}=\mathrm{R}_{1}=\mathrm{H} & \mathrm{R}_{2}=\mathrm{glc} & \mathrm{R}_{3}=\mathrm{Me} & \mathrm{R}_{4}=\mathrm{R}_{5}=\mathrm{OH}\end{array}$


Table 1. ${ }^{1} \mathrm{H}$ - and ${ }^{13} \mathrm{C}-\mathrm{NMR}$ data of compounds 1-2 $\left(\mathrm{CD}_{3} \mathrm{OD}, 600 \mathrm{MHz}\right)^{\mathrm{a}}$

\begin{tabular}{|c|c|c|c|c|c|}
\hline position & 1 & & & 2 & \\
\hline & $\delta_{\mathrm{H}}$ & $\delta_{\mathrm{C}}$ & & $\delta_{\mathrm{H}}$ & $\delta_{\mathrm{C}}$ \\
\hline 2 & & 159.0 & 2 & & 159.3 \\
\hline 3 & & 135.6 & 3 & & 136.0 \\
\hline 4 & & 179.0 & 4 & & 179.8 \\
\hline 5 & & 163.5 & 5 & & 163.5 \\
\hline 6 & $6.16 \mathrm{~d}(1.5)$ & 100.0 & 6 & $6.50 \mathrm{~d}(2.0)$ & 99.4 \\
\hline 7 & & 166.3 & 7 & & 165.8 \\
\hline 8 & $6.33 \mathrm{~d}(1.5)$ & 94.2 & 8 & $6.68 \mathrm{~d}(2.0)$ & 95.0 \\
\hline 9 & & 159.0 & 9 & & 158.9 \\
\hline 10 & & 105.8 & 10 & & 106.0 \\
\hline $1^{\prime}$ & & 123.1 & $1^{\prime}$ & & 122.0 \\
\hline $2^{\prime}$ & $7.65 \mathrm{~d}(2.0)$ & 117.2 & $2^{\prime}$ & $7.95 \mathrm{~d}(8.0)$ & 129.6 \\
\hline $3^{\prime}$ & & 148.0 & $3^{\prime}$ & $7.08 \mathrm{~d}(8.0)$ & 115.7 \\
\hline $4^{\prime}$ & & 145.0 & $4^{\prime}$ & & 159.0 \\
\hline $5^{\prime}$ & $6.97 \mathrm{~d}(8.5)$ & 118.0 & $5^{\prime}$ & $7.08 \mathrm{~d}(8.0)$ & 115.7 \\
\hline \multirow[t]{2}{*}{$6^{\prime}$} & $7.84 \mathrm{dd}(2.0,8.5)$ & 123.2 & $6^{\prime}$ & $7.95 \mathrm{~d}(8.0)$ & 129.6 \\
\hline & & & 4'-OMe & $3.90 \mathrm{~s}$ & 58.5 \\
\hline 3'-O-Glc 1" & $4.88 \mathrm{~d}(7.5)$ & 104.7 & 3-O-Glc1" & $5.27 \mathrm{~d}(7.8)$ & 103.5 \\
\hline $2^{\prime \prime}$ & $3.58 \mathrm{dd}(7.5,9.0)$ & 74.8 & $2^{\prime \prime}$ & $3.54 \mathrm{dd}(7.8,9.5)$ & 74.0 \\
\hline $3 "$ & $3.52 \mathrm{t}(9.0)$ & 77.3 & $3^{\prime \prime}$ & $3.50 \mathrm{t}(9.5)$ & 77.8 \\
\hline $4 "$ & $3.42 \mathrm{t}(9.0)$ & 71.2 & $4 "$ & $3.39 \mathrm{t}(9.5)$ & 71.6 \\
\hline $5^{\prime \prime}$ & $3.53 \mathrm{~m}$ & 78.4 & $5^{\prime \prime}$ & $3.60 \mathrm{~m}$ & 75.4 \\
\hline $6 " \mathrm{a}$ & $3.95 \mathrm{dd}(5.0,12.0)$ & 62.4 & $6 " \mathrm{a}$ & $4.34 \mathrm{dd}(12.0,4.5)$ & 64.5 \\
\hline 6"b & $3.79 \mathrm{dd}(3.5,12.0)$ & & 6"b & $4.24 \mathrm{dd}(12.0,3.0)$ & \\
\hline 3-O-Glc1"' & $5.26 \mathrm{~d}(7.5)$ & 103.4 & $p$-coumaroyl 1 & & 125.0 \\
\hline $2 " '$ & $3.56 \mathrm{dd}(7.5,9.0)$ & 73.6 & 2,6 & $7.95 \mathrm{~d}(8.0)$ & 129.7 \\
\hline $3^{\prime \prime \prime}$ & $3.50 \mathrm{t}(9.0)$ & 77.7 & 3,5 & $6.83 \mathrm{~d}(8.0)$ & 116.2 \\
\hline 4"' & $3.40 \mathrm{t}(9.0)$ & 71.8 & 4 & & 159.5 \\
\hline $5 " '$ & $3.59 \mathrm{~m}$ & 75.2 & $\alpha$ & $6.42 \mathrm{~d}(16.0)$ & 116.1 \\
\hline $6 " \mathrm{ma}$ & $4.32 \mathrm{dd}(12.0,5.0)$ & 64.2 & $\beta$ & $7.65 \mathrm{~d}(16.0)$ & 146.0 \\
\hline 6"'b & $4.23 \mathrm{dd}(12.0,3.5)$ & & $\mathrm{COO}$ & & 168.3 \\
\hline$p$-coumaroyl 1 & & 125.2 & & & \\
\hline 2,6 & $8.00 \mathrm{~d}(8.5)$ & 130.0 & & & \\
\hline 3,5 & $6.90 \mathrm{~d}(8.5)$ & 116.5 & & & \\
\hline 4 & & 159.0 & & & \\
\hline$\alpha$ & $6.40 \mathrm{~d}(16.0)$ & 116.0 & & & \\
\hline$\beta$ & $7.68 \mathrm{~d}(16.0)$ & 146.2 & & & \\
\hline $\mathrm{COO}$ & & 168.5 & & & \\
\hline
\end{tabular}

${ }^{\text {a }}$ Coupling pattern and coupling constants $(J$ in Hertz) are in parentheses. 
Table 2: ${ }^{1} \mathrm{H}$ - and ${ }^{13} \mathrm{C}-\mathrm{NMR}$ data of compounds 3-4 $\left(\mathrm{CD}_{3} \mathrm{OD}, 600 \mathrm{MHz}\right)^{\mathrm{a}}$

\begin{tabular}{|c|c|c|c|c|}
\hline Position & 3 & & 4 & \\
\hline & $\delta_{\mathrm{H}}$ & $\delta_{\mathrm{C}}$ & $\delta_{\mathrm{H}}$ & $\delta_{\mathrm{C}}$ \\
\hline 2 & & 158.2 & & 158.1 \\
\hline 3 & & 142.0 & & 134.5 \\
\hline 4 & & 179.0 & & 176.0 \\
\hline 5 & & 166.0 & $8.02 \mathrm{~d}(8.0)$ & 128.3 \\
\hline 6 & $6.51 \mathrm{~d}(2.0)$ & 97.0 & $6.95 \mathrm{dd}(8.0,2.0)$ & 116.9 \\
\hline 7 & & 162.2 & & 164.7 \\
\hline 8 & $6.85 \mathrm{~d}(2.0)$ & 93.4 & $6.93 \mathrm{~d}(2.0)$ & 103.3 \\
\hline 9 & & 158.5 & & 158.3 \\
\hline 10 & & 110.0 & & 103.0 \\
\hline $1^{\prime}$ & & 122.3 & & 122.0 \\
\hline $2^{\prime}$ & $8.04 \mathrm{~d}(2.0)$ & 118.3 & $7.30 \mathrm{~s}$ & 100.9 \\
\hline $3^{\prime}$ & & 148.0 & & 146.8 \\
\hline $4^{\prime}$ & & 145.3 & & 141.0 \\
\hline $5^{\prime}$ & $6.97 \mathrm{~d}(8.5)$ & 118.0 & & 146.8 \\
\hline $6^{\prime}$ & $7.83 \mathrm{dd}(2.0,8.5)$ & 126.5 & $7.30 \mathrm{~s}$ & 100.9 \\
\hline 3-OMe & $3.80 \mathrm{~s}$ & 60.0 & & \\
\hline $5-\mathrm{OMe}$ & $3.95 \mathrm{~s}$ & 56.5 & & \\
\hline 7-OMe & $3.92 \mathrm{~s}$ & 56.3 & & \\
\hline 4'-OMe & & & $3.90 \mathrm{~s}$ & 56.7 \\
\hline 3'-O-Glc 1" & $4.88 \mathrm{~d}(7.5)$ & 104.7 & & \\
\hline $2 "$ & $3.58 \mathrm{dd}(7.5,9.0)$ & 74.8 & & \\
\hline $3 "$ & $3.52 \mathrm{t}(9.0)$ & 77.3 & & \\
\hline $4 "$ & $3.42 \mathrm{t}(9.0)$ & 71.2 & & \\
\hline $5 "$ & $3.53 \mathrm{~m}$ & 78.4 & & \\
\hline $6 " \mathrm{a}$ & $3.95 \mathrm{dd}(12.0,5.0)$ & 62.4 & & \\
\hline 6"b & $3.79 \mathrm{dd}(12.0,3.5)$ & & & \\
\hline 3-O-Glc1" & & & $5.31 \mathrm{~d}(7.5)$ & 102.9 \\
\hline $2 "$ & & & $3.52 \mathrm{dd}(7.5,9.5)$ & 74.0 \\
\hline $3 "$ & & & $3.47 \mathrm{t}(9.5)$ & 78.1 \\
\hline $4 "$ & & & $3.39 \mathrm{t}(9.5)$ & 71.3 \\
\hline $5 "$ & & & $3.56 \mathrm{~m}$ & 77.7 \\
\hline $6 " \mathrm{a}$ & & & $3.90 \mathrm{dd}(12.0,5.0)$ & 62.9 \\
\hline $6 " \mathrm{~b}$ & & & $3.87 \mathrm{dd}(12.0,3.5)$ & \\
\hline
\end{tabular}

${ }^{a}$ Coupling pattern and coupling constants $(J$ in Hertz) are in parentheses.

To compound 2 was assigned the molecular formula $\mathrm{C}_{31} \mathrm{H}_{28} \mathrm{O}_{13}$ by ESI-MS $\left([\mathrm{M}-\mathrm{H}]^{-}\right.$peak at $\mathrm{m} / z$ 607), ${ }^{13} \mathrm{C}$ NMR (Table 1), and ${ }^{13} \mathrm{C}$ DEPT data. The ${ }^{1} \mathrm{H}$ NMR of 2 (Table 1) was very similar to $\mathbf{1}$ except for signals of ring $\mathrm{B}$ of the aglycon moiety that in $\mathbf{2}$ were typical of a kaempferol $4^{\prime}$-methyl ether. ${ }^{6}$ The ${ }^{1} \mathrm{H}$ NMR and ${ }^{13} \mathrm{C}$ NMR exhibited signals which can be ascribed to a kaempferol, $p$ coumaroyl, and methoxyl moieties along with those of one anomeric proton identified with the help 
of DQF-COSY and 1D-TOCSY as one glucose $(\delta 5.27, J=7.8 \mathrm{~Hz})$. The configuration of the glucose unit was determined as reported for compound $\mathbf{1}$. The assignments of all protonated carbons were accomplished by interpretation of the HSQC NMR spectrum while HMBC experiment correlations indicated connections between $\delta 5.27$ (H-1") and 136.0 (C-3), $\delta 4.24$ and $4.34\left(\mathrm{H}_{2}-6 "\right)$ and $168.3(\mathrm{COO}), \delta 3.90(\mathrm{OMe})$ and $159.0\left(\mathrm{C}-4^{\prime}\right)$. From these results, the structure of 2 was concluded to be kaempferol 4'-methyl ether 3-O-(6"-p-coumaroyl)- $\beta$-D-glucopyranoside.

The molecular formula $\mathrm{C}_{24} \mathrm{H}_{26} \mathrm{O}_{12}$ for compound 3 was determined by ESI-MS $\left([\mathrm{M}+\mathrm{H}]^{+}\right.$at $\mathrm{m} / \mathrm{z}$ 507), ${ }^{13} \mathrm{C},{ }^{13} \mathrm{C}$-DEPT NMR analyses and was supported also by elemental analysis. Its ${ }^{1} \mathrm{H}$ - and ${ }^{13} \mathrm{C}$ NMR spectra (see Table 2) indicated that it was a quercetin 3,5,7-trimethyl ether derivative. ${ }^{7}$ Its ${ }^{1} \mathrm{H}$ NMR spectrum further displayed signals for one sugar residues that were easily clarified with the help of 1D-TOCSY and DQF-COSY experiments, leading to the identification of one $\beta$-Dglucopyranosyl residue. The configuration of the glucose unit was determined as reported for compound 1. HMBC correlations [ $\delta 4.88\left(\mathrm{H}-1^{\prime \prime}\right)$ and $\left.148.0 \mathrm{ppm}\left(\mathrm{C}-3^{\prime}\right)\right]$ established the substitution sites of the glucose moiety and the three methoxyl groups, allowing compound $\mathbf{3}$ to be identified as quercetin 3,5,7-trimethyl ether 3'-O- $\beta$-D-glucopyranoside.

Compound 4 was assigned the molecular formula $\mathrm{C}_{22} \mathrm{H}_{22} \mathrm{O}_{12}\left([\mathrm{M}-\mathrm{H}]^{-}\right.$peak at $\left.m / z 477\right)$. Analysis of its MS, ${ }^{13} \mathrm{C}$, and ${ }^{13} \mathrm{C}$ DEPT NMR data indicated that it was a flavonoid with 16 carbon atoms assigned to the aglycon and 6 carbons to the sugar moieties. The $600 \mathrm{MHz}{ }^{1} \mathrm{H}$ NMR spectrum indicated an unusual 7-hydroxylated pattern for ring A (ABX system signals at $\delta 6.93, \mathrm{~d}, J=2.0$ $\mathrm{Hz} ; 6.95, \mathrm{dd}, J=8.0,2.0 \mathrm{~Hz} ; 8.02, \mathrm{~d}, J=8.0 \mathrm{~Hz}$ ) and a $3^{\prime}, 4^{\prime}, 5^{\prime}$-trihydroxylation pattern for ring B (two-proton singlet at $\delta$ 7.30), allowing the aglycon to be recognized as $3,7,3^{\prime}, 4^{\prime}, 5^{\prime}$ pentahydroxyflavone or robinetin. ${ }^{8,9}$ Except for the aglycon signals, the ${ }^{1} \mathrm{H}$ NMR spectrum of 4 revealed the presence of one-proton doublet at $\delta 5.31(J=7.5 \mathrm{~Hz})$ representative of one anomeric proton and of a three-proton singlet at $\delta 3.90$ attributable to a methoxyl group. Selected 1D TOCSY data, when compared with those obtained from the ${ }^{13} \mathrm{C}$ NMR and HSQC experiments, allowed the identification of the sugar as glucose with a $\beta$-configuration. The relative postions of the $\beta$-Dglucopyranose and methoxyl units were established from the HMBC correlations $\left[\delta 5.31\left(\mathrm{H}-1^{\prime \prime}\right)\right.$ with $134.5 \mathrm{ppm}(\mathrm{C}-3)$ and $\delta 3.90(\mathrm{OMe})$ with $141.0 \mathrm{ppm}\left(\mathrm{C}-4^{\prime}\right)$ ]. Compound 4 was therefore identified as $3,7,3^{\prime}, 5^{\prime}$-tetrahydroxy-4'-methoxyflavone 3-O- $\beta$-D-glucopyranoside.

Compound 5 displayed the molecular formula $\mathrm{C}_{24} \mathrm{H}_{32} \mathrm{O}_{8}$. Its ESI-MS spectrum revealed a molecular ion at $\mathrm{m} / \mathrm{z} 447$, together with ion at $\mathrm{m} / \mathrm{z} 285$, corresponding to the loss of one hexose unit. In the ${ }^{1} \mathrm{H}$ NMR spectrum of 5 (Table 3), two ortho-coupled aromatic protons (each $\mathrm{d}, \delta 6.95$ and $6.66, J=8.5 \mathrm{~Hz})$ and an isolated methylene group $(\mathrm{s}, \delta 3.56)$ were evident, suggesting the presence of an ortho-disubstituted 2(3H)-benzofuranone. ${ }^{10}$ Moreover the ${ }^{1} \mathrm{H}$ NMR data showed signals for three tertiary methyl $(\delta 1.82,1.63$, and 1.58), two olefinic protons ( $\delta 5.11$ and 5.09), and three methylene groups ( $\delta 3.62$ and 3.54, 2.09 and 1.99). A 1D-TOCSY subspectrum obtained by irradiating signal at $\delta 5.11$ showed a set of coupled protons at $\delta 3.62$ and $3.54\left(\mathrm{CH}_{2}\right)$ and $\delta 1.82$ $\left(\mathrm{CH}_{3}\right)$, while irradiating signal at $\delta 5.09$ the set of coupled protons at $\delta 2.09$ and 1.99 (both $\mathrm{CH}_{2}$ ) and $\delta 1.63$ and 1.58 (both $\mathrm{CH}_{3}$ ) was observed. Analysis of the correlated ${ }^{13} \mathrm{C}$ NMR signals in the HSQC spectrum and DQF-COSY led to the identification of a geranyl side chain. One sugar residue, easily recognizable as $\beta$-D-glucopyranose by 1D-TOCSY and DQF-COSY experiments, was also present. The D configuration of the glucose residue was established as reported for compound 1. All carbon and proton signals of the molecule 5 were assigned from the HSQC and HMBC experiments: long-range correlations between $\delta 3.56\left(\mathrm{H}_{2}-3\right)$ and $132.6(\mathrm{C}-4), 153.0(\mathrm{C}-7 \mathrm{a})$, 
and $180.8(\mathrm{C}-2)$, between $\delta 3.62$ and $3.54\left(\mathrm{H}_{2}-1^{\prime}\right)$ and $126.0(\mathrm{C}-3 \mathrm{a}), 132.6(\mathrm{C}-4), 135.2\left(\mathrm{C}-3^{\prime}\right)$, and $150.8(\mathrm{C}-5)$, and between $\delta 4.79\left(\mathrm{H}-1^{\prime \prime}\right)$ and $150.8 \mathrm{ppm}(\mathrm{C}-5)$, restricted the location of the geranyl side chain and glucose moiety to $\mathrm{C}-4$ and $\mathrm{C}-5$, respectively. Thus, the new compound 5 was characterized as 4-geranyl-5-O- $\beta$-D-glucopyranosyl-2(3H)-benzofuranone. This is the first report of a 2(3H)-benzofuranone from a Vernonia species. The aglycon of compound $\mathbf{5}$ was previously identified from Mimulus clevelandii. ${ }^{10}$

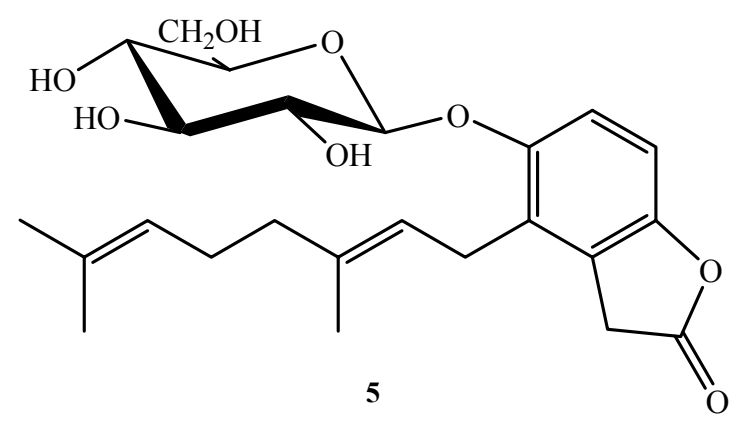

Compound 6 gave molecular formula $\mathrm{C}_{19} \mathrm{H}_{24} \mathrm{O}_{8}$ as determined from ${ }^{13} \mathrm{C},{ }^{13} \mathrm{C}$ DEPT NMR, and ESI-MS analyses ([M-H] $]^{-}$peak at $\left.m / z 379\right)$. The analysis of the NMR data of 6 and the comparison with those of 5 revealed signals completely superimposable, except for those of the side chain, consisting in five carbon skeleton in $\mathbf{6}$ instead of ten in 5. Particularly, in the ${ }^{1} \mathrm{H}$ NMR spectrum of 6 were evident signals for two tertiary methyl ( $\delta 1.81$ and 1.66$)$, one olefinic protons $(\delta 5.13)$, and one methylene group ( $\delta 3.56)$ ascribable to an emiterpene unit. The structure elucidation of 6 was achieved by 1D-TOCSY, DQF-COSY, HSQC, and HMBC experiments allowing to identify 6 as 4isoprenyl-5-O- $\beta$-D-glucopyranosyl-2(3H)-benzofuranone.

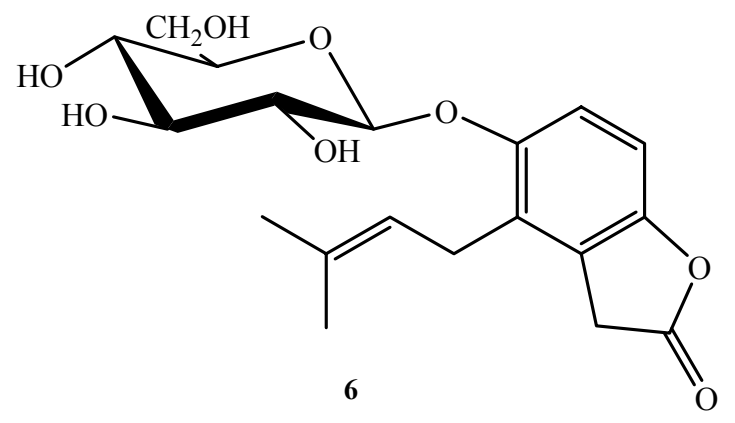

Four known flavonoids, quercetin, rutin, acacetin 7-O-rutinoside, and quercetin 3-O-(6"caffeoyl)- $\beta$-D-glucopyranoside were identified by means of $1 \mathrm{D}$ - and 2D-NMR spectroscopy, ESIMS analysis, and by comparison of their data with those reported in the literature. ${ }^{6,11,12}$ 
Table 3. ${ }^{1} \mathrm{H}$ - and ${ }^{13} \mathrm{C}-\mathrm{NMR}$ data of compounds 5-6 $\left(\mathrm{CD}_{3} \mathrm{OD}, 600 \mathrm{MHz}\right)^{\mathrm{a}}$

\begin{tabular}{|c|c|c|c|c|}
\hline position & 5 & & 6 & \\
\hline & $\delta_{\mathrm{H}}$ & $\delta_{\mathrm{C}}$ & $\delta_{\mathrm{H}}$ & $\delta_{\mathrm{C}}$ \\
\hline 2 & & 180.8 & & 181.2 \\
\hline 3 & $3.56 \mathrm{~s}$ & 38.4 & $3.58 \mathrm{~s}$ & 38.4 \\
\hline $3 a$ & & 126.0 & & 126.0 \\
\hline 4 & & 132.6 & & 132.0 \\
\hline 5 & & 150.8 & & 150.0 \\
\hline 6 & $6.95 \mathrm{~d}(8.5)$ & 116.4 & $6.69 \mathrm{~d}(8.0)$ & 115.9 \\
\hline 7 & $6.66 \mathrm{~d}(8.5)$ & 115.6 & $6.97 \mathrm{~d}(8.0)$ & 116.8 \\
\hline $7 \mathrm{a}$ & & 153.0 & & 153.0 \\
\hline 1 'a & $3.54 \mathrm{dd}(15.0,7.0)$ & 26.7 & $3.52 \mathrm{dd}(14.8,7.0)$ & 27.0 \\
\hline $1 ' b$ & $3.62 \mathrm{dd}(15.0,7.0)$ & & $3.62 \mathrm{dd}(14.8,7.0)$ & \\
\hline $2^{\prime}$ & $5.11 \mathrm{~m}$ & 125.1 & 5.13 br t $(7.0)$ & 125.3 \\
\hline $3^{\prime}$ & & 135.2 & & 135.2 \\
\hline $4^{\prime}$ & $1.82 \mathrm{~s}$ & 16.7 & $1.81 \mathrm{~s}$ & 24.0 \\
\hline $5^{\prime}$ & 1.99 t (7.5) & 41.0 & $1.66 \mathrm{~s}$ & 17.5 \\
\hline $6^{\prime}$ & $2.09 \mathrm{dd}(7.5,1.5)$ & 27.8 & & \\
\hline $7^{\prime}$ & $5.09 \mathrm{~m}$ & 125.6 & & \\
\hline $8^{\prime}$ & & 132.1 & & \\
\hline $9^{\prime}$ & $1.63 \mathrm{~s}$ & 25.9 & & \\
\hline $10^{\prime}$ & $1.58 \mathrm{~s}$ & 17.8 & & \\
\hline$O$-Glc 1" & $4.79 \mathrm{~d}(7.5)$ & 104.0 & $4.81 \mathrm{~d}(7.5)$ & 104.7 \\
\hline 2" & $3.46 \mathrm{dd}(7.5,9.0)$ & 75.2 & $3.51 \mathrm{dd}(7.5,9.0)$ & 75.9 \\
\hline $3 "$ & 3.44 t $(9.0)$ & 78.2 & $3.38 \mathrm{t}(9.0)$ & 78.8 \\
\hline $4 "$ & $3.38 \mathrm{t}(9.0)$ & 71.5 & $3.28 \mathrm{t}(9.0)$ & 72.0 \\
\hline $5 "$ & $3.36 \mathrm{~m}$ & 78.2 & $3.49 \mathrm{~m}$ & 78.8 \\
\hline $6 " \mathrm{a}$ & $3.88 \mathrm{dd}(12.0,5.0)$ & 62.7 & $3.91 \mathrm{dd}(12.0,5.0)$ & 63.0 \\
\hline $6 " \mathrm{~b}$ & $3.71 \mathrm{dd}(12.0,3.5)$ & & $3.74 \mathrm{dd}(12.0,3.5)$ & \\
\hline
\end{tabular}

${ }^{\text {a }}$ Coupling pattern and coupling constants $(J$ in Hertz) are in parentheses.

\section{Experimental Section}

General Procedures. Optical rotations were measured on a Perkin-Elmer 241 polarimeter equipped with a sodium lamp (589 $\mathrm{nm}$ ) and a $10 \mathrm{~cm}$ microcell. Elemental analysis was obtained from a Carlo Erba 1106 elemental analyzer. UV spectra were recorded on a Perkin-Elmer-Lambda 12 spectrophotometer. A Bruker DRX-600 NMR spectrometer using the UXNMR software package was used for NMR experiments. ESIMS (positive and negative mode) were obtained using a Finnigan LC-Q Advantage Termoquest spectrometer, equipped with Xcalibur software. TLC was performed on precoated Kieselgel $60 \mathrm{~F}_{254}$ plates (Merck, Darmstadt, Germany); compounds were detected by spraying with $\mathrm{Ce}\left(\mathrm{SO}_{4}\right)_{2} / \mathrm{H}_{2} \mathrm{SO}_{4}$ (Sigma-Aldrich, St. Louis, Mo, USA) and NTS (Naturstoffe reagent)-PEG (Polyethylene glycol 4000) solutions. Column chromatography was 
performed over Sephadex LH-20 (Pharmacia); reversed-phase (RP) HPLC separations were conducted on a Waters 515 pumping system equipped with a Waters R401 refractive index detector and Waters U6K injector, using a $\mathrm{C}_{18} \mu$-Bondapak column $(30 \mathrm{~cm} \times 7.8 \mathrm{~mm})$ and a mobile phase consisting of $\mathrm{MeOH}-\mathrm{H}_{2} \mathrm{O}$ mixtures at a flow rate of $2 \mathrm{~mL} / \mathrm{min}$. $\mathrm{GC}$ analyses were performed using a Dani GC 1000 instrument.

Plant material. The aerial parts of Vernonia mapirensis Gleason were collected in Cotapata, Bolivia, in 2001. A voucher specimen (Michel R de y Morale L. No. 2991 HNB) is deposited at the Herbario Nacional de Bolivia.

Extraction and isolation. The dried powdered leaves of $V$. mapirensis (500 g) were extracted with $n$-hexane, $\mathrm{CHCl}_{3}, \mathrm{CHCl}_{3}-\mathrm{MeOH}(9: 1)$, and $\mathrm{MeOH}$, by Accelerated Solvent Extraction (ASE), to give 19.5, 18.0, 13.0, and $18.5 \mathrm{~g}$ of the respective residues. The methanol extract (18.5 $\mathrm{g})$ was partitioned between $n$ - $\mathrm{BuOH}$ and $\mathrm{H}_{2} \mathrm{O}$ to give a $n$ - $\mathrm{BuOH}$ soluble portion $(3.6 \mathrm{~g})$ which was chromatographed over a Sephadex LH-20 column $(100 \mathrm{~cm} \mathrm{x} 3 \mathrm{~cm})$ with $\mathrm{MeOH}$ as eluent. A total of 50 fractions were collected $\left(8 \mathrm{~mL}\right.$ each) and combined according to TLC analysis [silica $60 \mathrm{~F}_{254}$ gel-coated glass sheets with $n$ - $\mathrm{BuOH}-\mathrm{AcOH}-\mathrm{H}_{2} \mathrm{O}$ (60:15:25) and $\mathrm{CHCl}_{3}-\mathrm{MeOH}-\mathrm{H}_{2} \mathrm{O}$ (40:9:1)] to give five pooled fractions (A-E) together with pure quercetin 3-O-(6"-caffeoyl)- $\beta$-Dglucopyranoside and quercetin. Fraction $\mathrm{C}(270 \mathrm{mg})$ was purified by RP-HPLC on a $\mathrm{C}_{18} \mu$ Bondapak column $\left(30 \mathrm{~cm}\right.$ x $7.8 \mathrm{~mm}$, flow rate $\left.2.0 \mathrm{~mL} \mathrm{~min}{ }^{-1}\right)$ using $\mathrm{MeOH}-\mathrm{H}_{2} \mathrm{O}$ (4.7:5.3) to give rutin $\left(20 \mathrm{mg}, t_{\mathrm{R}}=16 \mathrm{~min}\right)$, compounds $1\left(10 \mathrm{mg}, t_{\mathrm{R}}=19 \mathrm{~min}\right)$, and $2\left(6 \mathrm{mg}, t_{\mathrm{R}}=29 \mathrm{~min}\right)$. Fraction $\mathrm{D}(150 \mathrm{mg})$ was purified by RP-HPLC on a $\mathrm{C}_{18} \mu$-Bondapak column $(30 \mathrm{~cm} \times 7.8 \mathrm{~mm}$, flow rate $\left.2.0 \mathrm{~mL} \mathrm{~min}{ }^{-1}\right)$ using $\mathrm{MeOH}-\mathrm{H}_{2} \mathrm{O}(5.5: 4.5)$ to yield compounds $3\left(12 \mathrm{mg}, t_{\mathrm{R}}=29 \mathrm{~min}\right), 4\left(7 \mathrm{mg}, t_{\mathrm{R}}=\right.$ $33 \mathrm{~min}$ ), and acacetin 7-O-rutinoside ( $4 \mathrm{mg}, t_{\mathrm{R}}=40 \mathrm{~min}$ ). A portion of the $\mathrm{CHCl}_{3}-\mathrm{MeOH}$ residue (4.0 g) was chromatographed on Sephadex LH-20 using MeOH as eluent; fractions of $8 \mathrm{~mL}$ were collected and grouped into nine major fractions (A-I) by TLC results on silica $60 \mathrm{~F}_{254}$ gel-coated glass sheets with $n$-BuOH-AcOH- $\mathrm{H}_{2} \mathrm{O}(60: 15: 25)$ and $\mathrm{CHCl}_{3}-\mathrm{MeOH}-\mathrm{H}_{2} \mathrm{O}$ (40:9:1). Fraction D (100 $\mathrm{mg}$ ) was purified by RP-HPLC on a $\mathrm{C}_{18} \mu$-Bondapak column $(30 \mathrm{~cm} \times 7.8 \mathrm{~mm}$, flow rate $2.0 \mathrm{~mL}$ $\min ^{-1}$ ) using $\mathrm{MeOH}-\mathrm{H}_{2} \mathrm{O}(2: 3)$ as eluent, to yield pure compounds 6 (4 $\left.\mathrm{mg}, t_{\mathrm{R}}=9 \mathrm{~min}\right)$ and 5 (15 $\left.\mathrm{mg}, t_{\mathrm{R}}=12 \mathrm{~min}\right)$. Fraction $\mathrm{E}$ was purified by RP-HPLC on a $\mathrm{C}_{18} \mu$-Bondapak column $(30 \mathrm{~cm} \times 7.8$ $\mathrm{mm}$, flow rate $\left.2.0 \mathrm{~mL} \mathrm{~min}^{-1}\right)$ using $\mathrm{MeOH}-\mathrm{H}_{2} \mathrm{O}(1: 1)$ as eluent to obtain rutin $\left(20 \mathrm{mg}, t_{\mathrm{R}}=12 \mathrm{~min}\right)$.

Quercetin 3-O-(6"-p-coumaroyl)- $\beta$-D-glucopyranoside-3'- $\boldsymbol{O}$ - $\boldsymbol{\beta}$-D-glucopyranoside (1). Yellow amorphous powder, $[\alpha]_{\mathrm{D}}:-21^{\circ}(c 0.1, \mathrm{MeOH}),{ }^{1} \mathrm{H}$ and ${ }^{13} \mathrm{C}$ NMR $\left(600 \mathrm{MHz}, \mathrm{CD}_{3} \mathrm{OD}\right)$ : see Table 1, ESIMS: $m / z 771$ [M-H]', Anal. Calcd for $\mathrm{C}_{36} \mathrm{H}_{36} \mathrm{O}_{19}$ : C, 55.96; H, 4.70. Found C, 56.00; H 4.72.

Kaempferol 4'-methyl ether 3-O-(6"'-p-coumaroyl)- $\beta$-D-glucopyranoside (2). Yellow amorphous powder, $[\alpha]_{\mathrm{D}}$ : $-44^{\circ}(c 0.1, \mathrm{MeOH}),{ }^{1} \mathrm{H}$ and ${ }^{13} \mathrm{C}$ NMR $\left(600 \mathrm{MHz}, \mathrm{CD}_{3} \mathrm{OD}\right)$ : see Table 1, ESIMS: $\mathrm{m} / z$ 607 [M-H]', Anal. Calcd for $\mathrm{C}_{31} \mathrm{H}_{28} \mathrm{O}_{13}$ : C, 61.18; H, 4.64. Found C, 61.14; H 4.67.

Quercetin 3,5,7-trimethyl ether 3'-O- $\beta$-D-glucopyranoside (3). Yellow amorphous powder, $[\alpha]_{\mathrm{D}}$ : $+32^{\circ}(c 0.1, \mathrm{MeOH}),{ }^{1} \mathrm{H}$ and ${ }^{13} \mathrm{C}$ NMR $\left(600 \mathrm{MHz}, \mathrm{CD}_{3} \mathrm{OD}\right)$ : see Table 2, ESIMS: $m / z 507[\mathrm{M}+\mathrm{H}]^{+}$, $345[\mathrm{M}+\mathrm{H}-162]^{+}, 330[\mathrm{M}+\mathrm{H}-162-15]^{+}$, Anal. Calcd for $\mathrm{C}_{24} \mathrm{H}_{26} \mathrm{O}_{12}: \mathrm{C}, 56.92 ; \mathrm{H}, 5.17$. Found $\mathrm{C}$, 57.00; H 5.13.

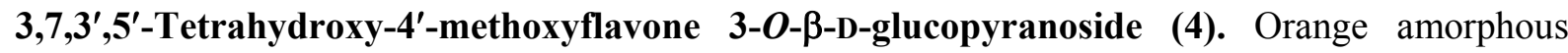
powder, $[\alpha]_{\mathrm{D}}:+36^{\circ}(c 0.1, \mathrm{MeOH}),{ }^{1} \mathrm{H}$ and ${ }^{13} \mathrm{C} \mathrm{NMR}\left(600 \mathrm{MHz}, \mathrm{CD}_{3} \mathrm{OD}\right)$ : see Table 2, ESIMS: $\mathrm{m} / z$ 477 [M-H]', Anal. Calcd for $\mathrm{C}_{22} \mathrm{H}_{22} \mathrm{O}_{12}$ : C, 55.23; H, 4.64. Found C, 55.20; H 4.61. 
4-Geranyl-5- $\boldsymbol{O}$ - $\boldsymbol{\beta}$-D-glucopyranosyl-2(3H)-benzofuranone (5). Amorphous powder, $\mathrm{UV} / \mathrm{V}$ is $\boldsymbol{\lambda}_{\max }$ $(\mathrm{MeOH}) \mathrm{nm}(\log \varepsilon): 218$ (4.09), 295 (3.50), ${ }^{1} \mathrm{H}$ and ${ }^{13} \mathrm{C}$ NMR (600 MHz, $\left.\mathrm{CD}_{3} \mathrm{OD}\right)$ : see Table 3, ESIMS: $m / z 447$ [M-H]', 285 [M-H-162]', Anal. Calcd for $\mathrm{C}_{24} \mathrm{H}_{32} \mathrm{O}_{8}: \mathrm{C}, 64.27 ; \mathrm{H}, 7.19$. Found C, 64.24; H 7.20.

4-Isoprenyl-5- $\boldsymbol{O}$ - $\beta$-D-glucopyranosyl-2(3H)-benzofuranone (6). Amorphous powder, UV/Vis $\lambda_{\max }(\mathrm{MeOH}) \mathrm{nm}(\log \varepsilon): 216$ (4.15), 290 (3.71), ${ }^{1} \mathrm{H}$ and ${ }^{13} \mathrm{C}$ NMR (600 MHz, $\left.\mathrm{CD}_{3} \mathrm{OD}\right)$ : see Table 3, ESIMS: $m / z 379$ [M-H]', 217 [M-H-162]', Anal. Calcd for $\mathrm{C}_{19} \mathrm{H}_{24} \mathrm{O}_{8}: \mathrm{C}, 59.99 ; \mathrm{H}, 6.36$. Found C, $60.05 ; \mathrm{H} 6.37$.

Acid hydrolysis of compounds 1-6. A solution of each compound (1-6, $2.0 \mathrm{mg}$ each) in $1 \mathrm{~N} \mathrm{HCl} \mathrm{(1}$ $\mathrm{mL}$ ) was stirred at $80{ }^{\circ} \mathrm{C}$ in a stoppered reaction vial for $4 \mathrm{~h}$. After cooling, the solution was evaporated under a stream of $\mathrm{N}_{2}$. Each residue was dissolved in 1-(trimethylsilyl)imidazole and pyridine $(0.2 \mathrm{~mL})$, and the solution was stirred at $60{ }^{\circ} \mathrm{C}$ for $5 \mathrm{~min}$. After drying the solution, the residue was partitioned between water and $\mathrm{CHCl}_{3}$. The $\mathrm{CHCl}_{3}$ layer was analyzed by $\mathrm{GC}$ using an L-CP-Chirasil-Val column $(0.32 \mathrm{~mm}$ x $25 \mathrm{~m})$. Temperatures of the injector and detector were 200 ${ }^{\circ} \mathrm{C}$ for both. A temperature gradient system was used for the oven, starting at $100{ }^{\circ} \mathrm{C}$ for $1 \mathrm{~min}$ and increasing up to $180{ }^{\circ} \mathrm{C}$ at a rate of $5{ }^{\circ} \mathrm{C} / \mathrm{min}$. Peaks of the hydrolysate were detected by comparison with retention times of authentic sample of D-glucose (Sigma Aldrich) after treatment with 1(trimethylsilyl)imidazole in pyridine.

\section{Acknowledgements}

Authors are grateful to Ing. Rossi de Michel of the Herbario Nacional de Bolivia for the help in collecting the plant material. This work was supported by the "Bioactive Compounds from Medicinal and Food Plants of Developing Countries" project of the Italian Ministry for University and Research (Ministero dell'Università e della Ricerca, MIUR).

\section{References and Footnotes}

1. Hilgert, N. I. J. Etnopharmacol. 2001, 76, 11.

2. Igile, G.; Oleszek, W.; Jurzysta, M.; Aquino, R.; De Tommasi, N.; Pizza, C. J. Nat. Prod. 1995, $58,1438$.

3. Miserez, F.; Potterat, O.; Marston, A.; Mungai, G. M.; Hostettmann, K. Phytochemistry 1996, 43, 283.

4. Sanogo, R.; Germanò, M. P.; De Tommasi, N.; Pizza, C.; Equino, R. Phytochemistry 1998, 47, 73.

5. Cioffi, G.; Sanogo, R.; Diallo, D.; Romussi, G.; De Tommasi, N. J. Nat. Prod. 2004, 67, 389.

6. Agrawal, P. K. Carbon-13 NMR of Flavonoids. Elsevier Science: Amsterdam, 1989; pp 294364.

7. Wang, Y.; Hamburger, M.; Gueho, J.; Hostettmann, K. Phytochemistry 1989, 28, 2323.

8. Batterham, T. J.; Highet, R. J. Aust. J. Chem. 1964, 17, 428.

9. Pietrogrande, M. C.; Reschiglian, P. L.; Dondi, F.; Kahie, Y. D.; Bertolasi, V. J. Chromatogr. 1992, 592, 65 . 
10. Phillips, W. R.; Baj, N. J.; Gunatilaka, A. A. L.; Kingston, D. G. I. J. Nat. Prod. 1996, 59, 495.

11. Ishimaru, K.; Matsura, E. Recent Res. Devel. Phytochem. 2000, 4, 49.

12. Calzada, F.; Cedillo-Rivera, R.; Mata, R. J. Nat. Prod. 2001, 64, 671. 